\title{
COMPUTER AIDED NONLINEAR ANALYSIS OF MACHINE TOOL VIBRATIONS AND A DEVELOPED COMPUTER SOFTWARE
}

\author{
Ahmet Taskesen \\ Department of Mechanical Education, Gazi University, 06500, Ankara, Turkey \\ Yucel Ercan \\ Department of Mechanical Engineering, TOBB Economics and Technology University, \\ 06560, Ankara, Turkey
}

\begin{abstract}
A computer program package is developed by using Visual Basic programming language in order to analyze one and two degree of freedom of machine tool chatter vibrations. The developed software accepts the machine tool properties, work piece properties and cutting parameters as inputs, calculates the time responses of selected cutting parameters and displays the results in graphical form. Hence the appropriate values of cutting parameters can be predicted for chatter-free operation of the machine tool.
\end{abstract}

Keywords- Computer simulation, Computer-aided analysis, Numerical analysis, Nonlinear vibrations, Dynamical modeling,

\section{INTRODUCTION}

Generally, a violent vibration of the tool, which is called chatter, negatively affects machining of metals. The most important property of chatter is that it is a self-excited vibration, which is closely related to the dynamic behavior of the cutting forces and the machinery structure. This is an undesirable condition because it adversely affects the surface finish quality, machining accuracy, tool life and spindle bearing life. In addition, chatter is also responsible for reducing production output because, if no solution can be found, metal removal rates have to be lowered until vibration-free performance is obtained. Furthermore, chatter is so inconsistent in character that the tendency of a machine to exhibit chatter is often not realized during the development stage [1].

In this study, chatter dynamics, which is modeled by one and two degree in $[1,2]$, is transferred to the computer by using Visual Basic programming language. By this software, after inputting the cutting parameters by the user; vibrations of tool displacement, shear angle, friction coefficient and cutting forces can be obtained easily.

MATLAB and Visual Basic softwares are used interactively for the solution of numerical equations. Since the dynamic equations related to vibration analysis are very complex, these equations are solved numerically. For the solution of these complex equations, some libraries of MATLAB software package are used in Visual Basic program. Fourth order Runga-Kutta method is used for numerical integration of the dynamic equation.

\section{DEVELOPED COMPUTER SOFTWARE}

A computer program is developed by using Visual Basic programming language in order to analyze machine tool chatter vibrations. The first module of this software is about turning operations. The menus such as milling, drilling and grinding are included to the software for the future developments (Figure 1). Some dialogue menus are used for data input and result output. At any time that one needs help, help menu could be selected. After selecting the operation type, the main menu appears for inputting cutting tool geometry, machine tool properties, work-piece material and cutting parameters 
(Figure 2). In chatter vibration analysis, the parameters that the user wants to see as output can be selected from sub menu called General. Machine tool properties are asked in Machine Tool submenu as seen in Figure 3. The stiffness and damping of the machine tool in $\mathrm{x}$ and $\mathrm{y}$ direction and mode angle are inputted. Selection of work piece material is seen from Figure 4. Selection of work piece material can be chosen from material library or the user can define new materials. Selection of cutting parameters is seen from Figure 5. Feed rate of the cutting tool, revolution number of work piece, cutting velocity, cutting width and ploughing force coefficient are input by the user.

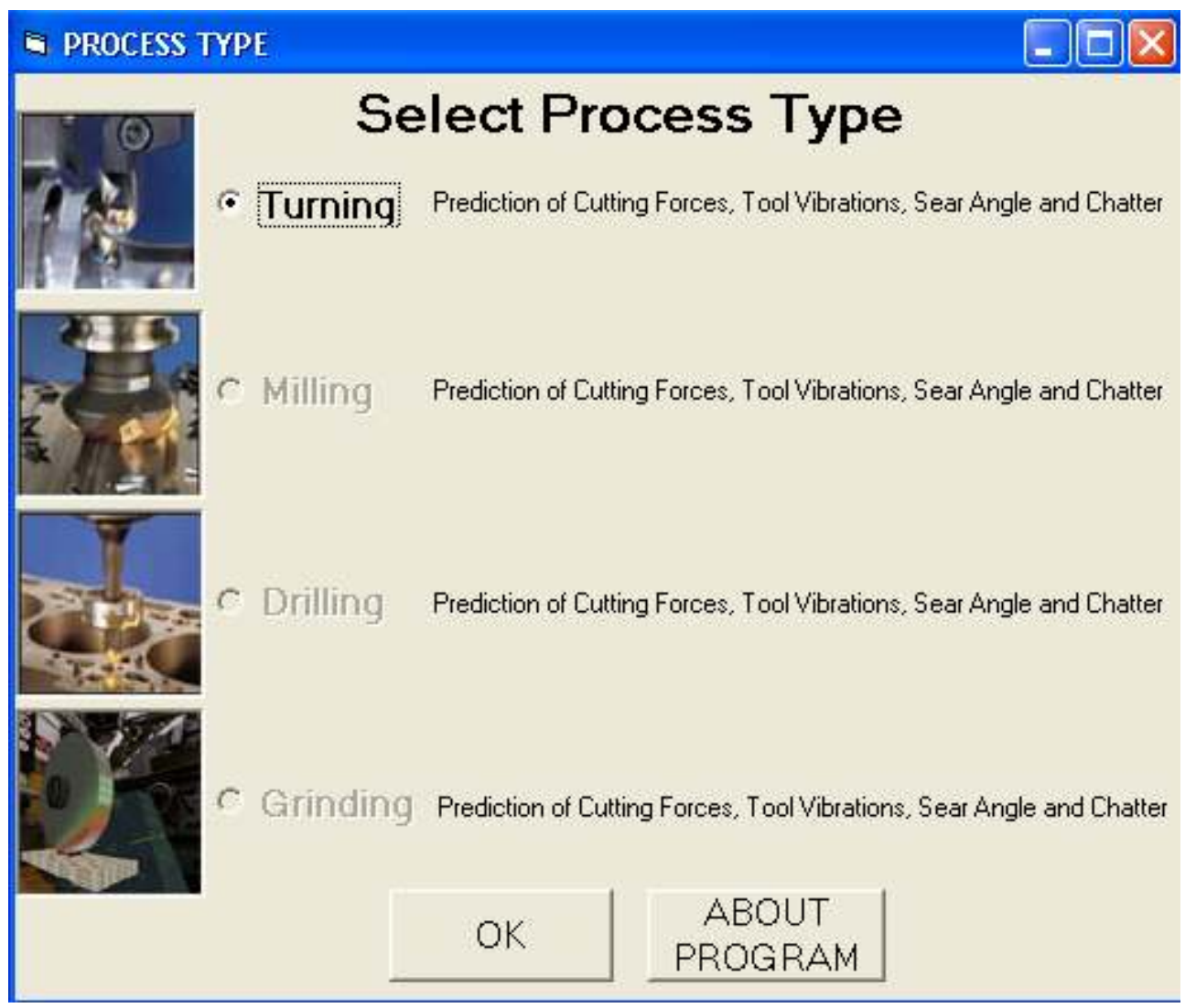

Figure1 Selection of process type 


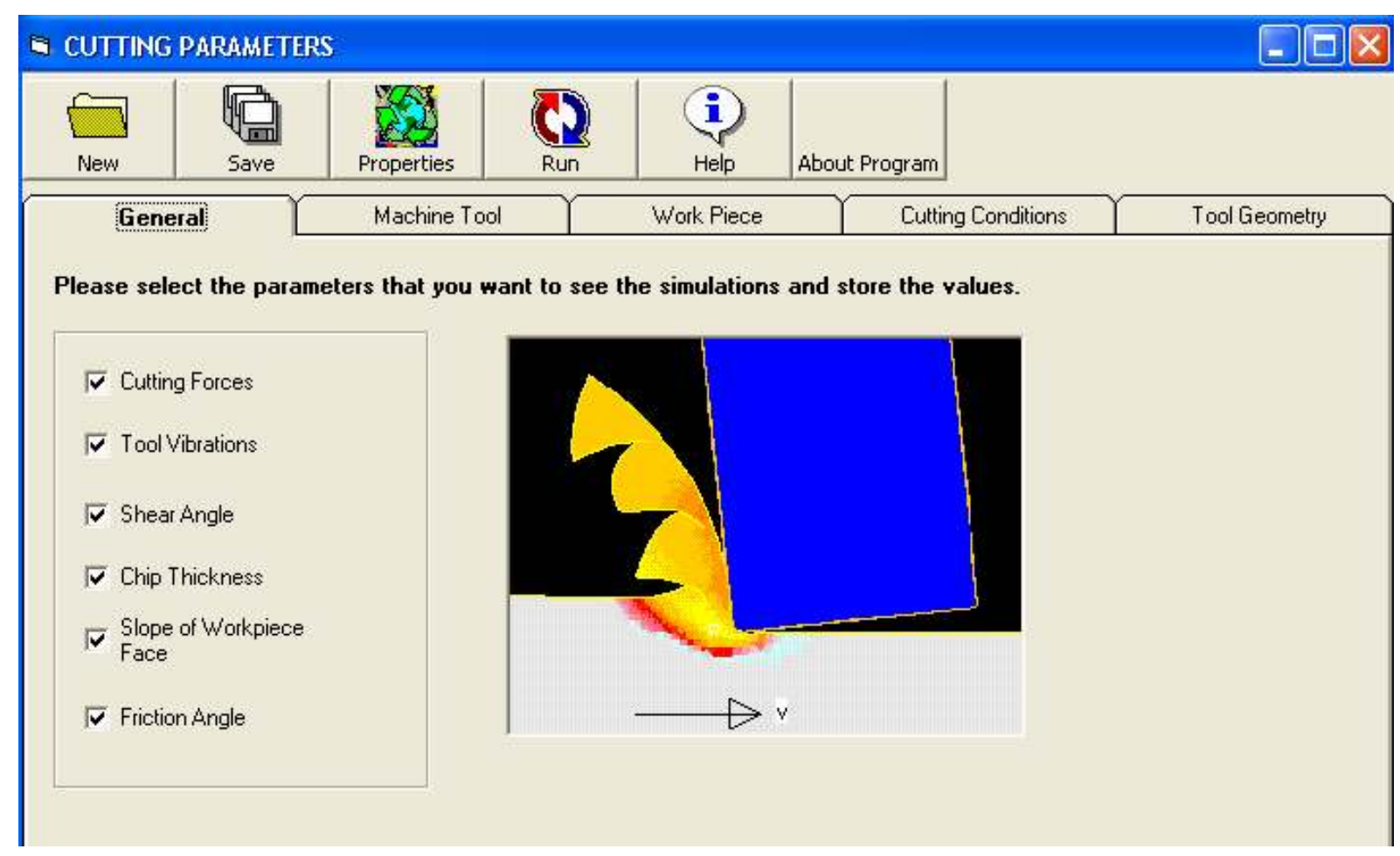

Figure 2 Main menu and simulation number

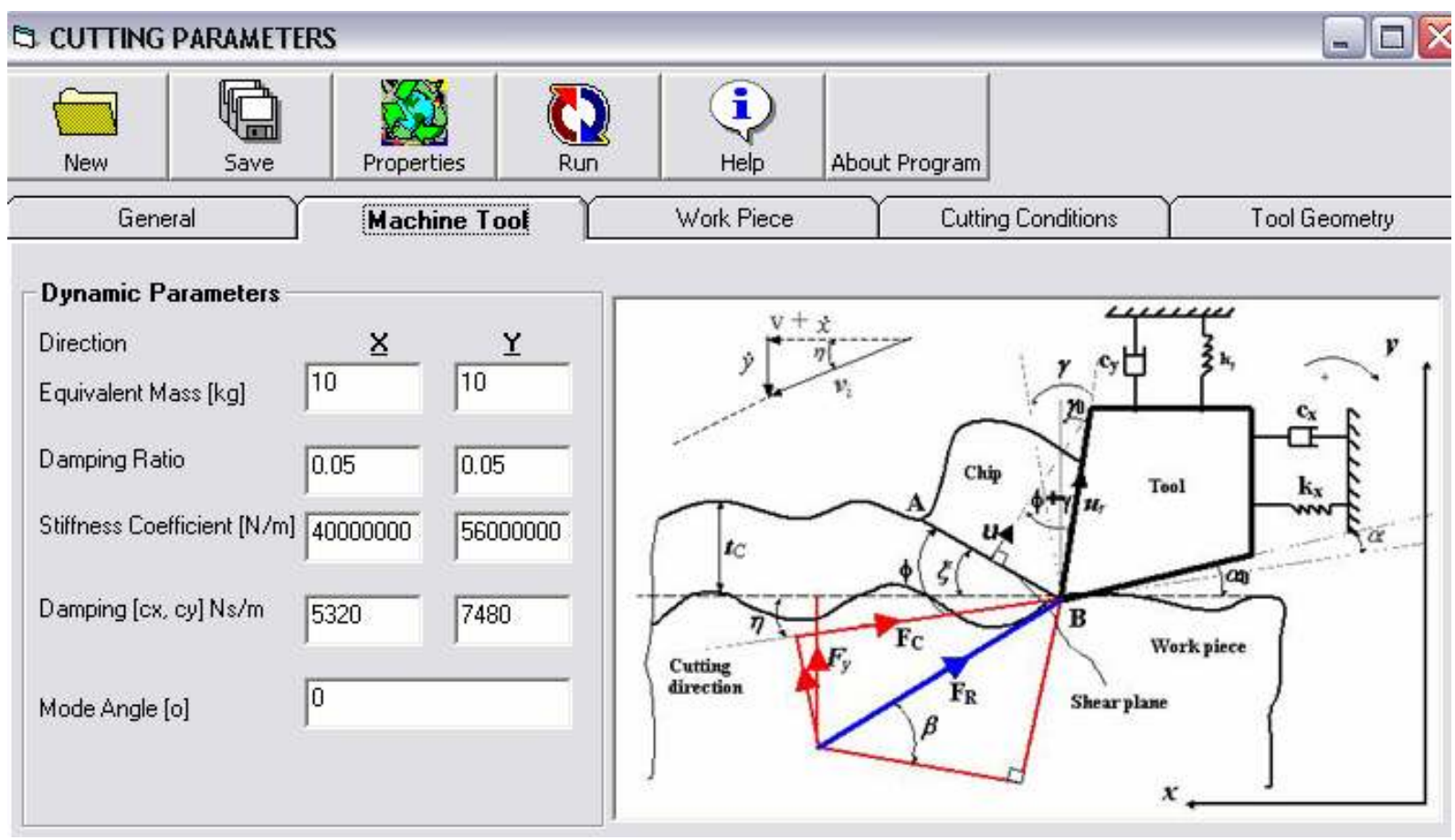

Figure 3 Inputting of Machine tool properties 


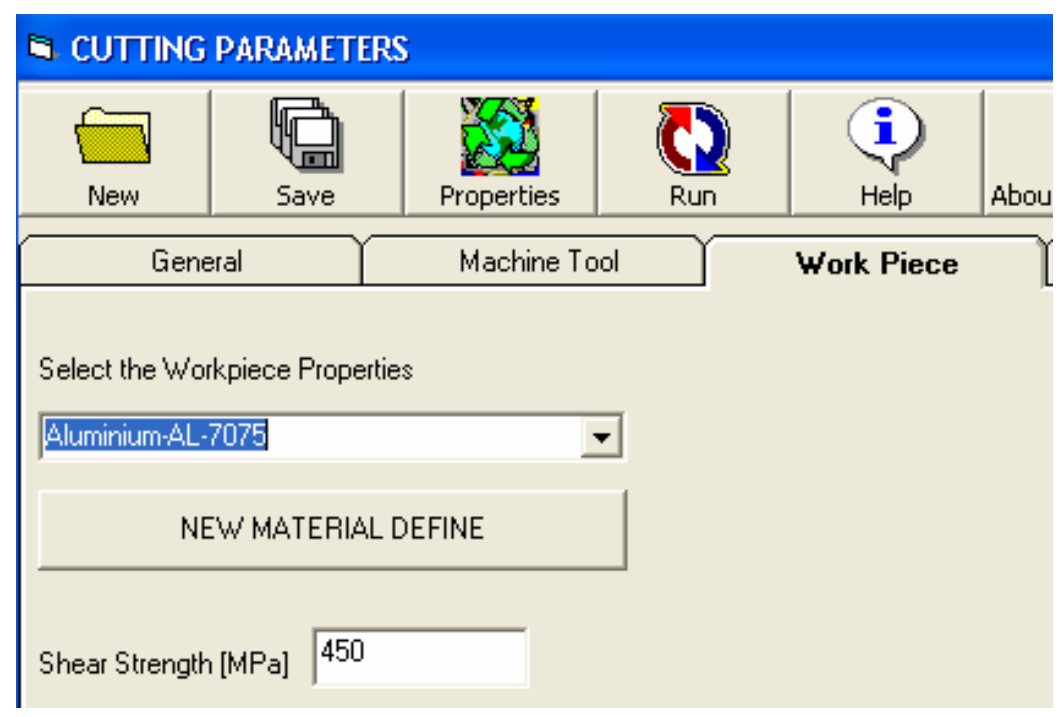

Figure 4 Selection of work piece material properties

Finally, cutting tool parameters such as clearance angle and rake angle are asked as seen from Figure 6.

After inputting all of the cutting parameters by the user, dynamic equations are solved and variations of selected variables can be obtained. The program numerically solves the dynamic equations. Flow chart of the numerical calculation procedure is shown in figure 7 . At the beginning of calculations, cutting parameters, material properties and machine tool properties are input. Then, shear angle $\phi$ and cutting forces are calculated by using the dynamic equations that are developed in the models of [1] and [2]; cutting tool position and velocity values are obtained by integrating dynamic equation numerically. Then, the time is incremented by $\Delta \mathrm{t}$ and the calculations are repeated until the final time $t_{f}$ is reached. Fourth order Runga-Kutta method is used for numerical integration of the dynamic equation. Variations of the variables that are selected as output by the user, and vibration amplitude of these variables are obtained. Results are presented numerically and graphically (Figure 8). If results are not suitable (i.e. there is chatter vibration), cutting parameters that are free from chatter can be searched by changing various cutting parameters that affects the results. Finally, suitable cutting parameters free from chatter vibrations can be obtained.

Equations which are developed in dynamic models of Taskesen and Ercan [1,2] and which are used for this software package are as follows:

Angle equations:

$$
\begin{aligned}
& q d\left(\frac{\bar{V} \sin \phi}{\operatorname{Cos}(\phi+\gamma)}+\bar{A}\right)^{q-1} \bar{v} \operatorname{sign}\left(\frac{\bar{V} \sin \phi}{\cos (\phi+\gamma)}+\bar{A}\right) \sin \phi \sin (\phi+\eta) \cos \gamma-\cos (\beta+\gamma) \cos ^{2}(\phi+\gamma) . \\
& \cos (2 \phi+\beta+\gamma+\eta)\left[1+d^{2}\left(\frac{\bar{V} \sin \phi}{\cos (\phi+\gamma)}+\bar{A}\right)^{2 q}\right]=0
\end{aligned}
$$
data.

Here, the parameters $\mathrm{d}$ and $\mathrm{q}(\mathrm{q}<0)$ are determined from the steady state cutting

$\phi=$ Shear plane angle, $\gamma=$ Instantaneous rake angle, $\bar{v}=$ dimensionless cutting speed, $\eta=$ Surface slope of instantaneous cutting direction. 


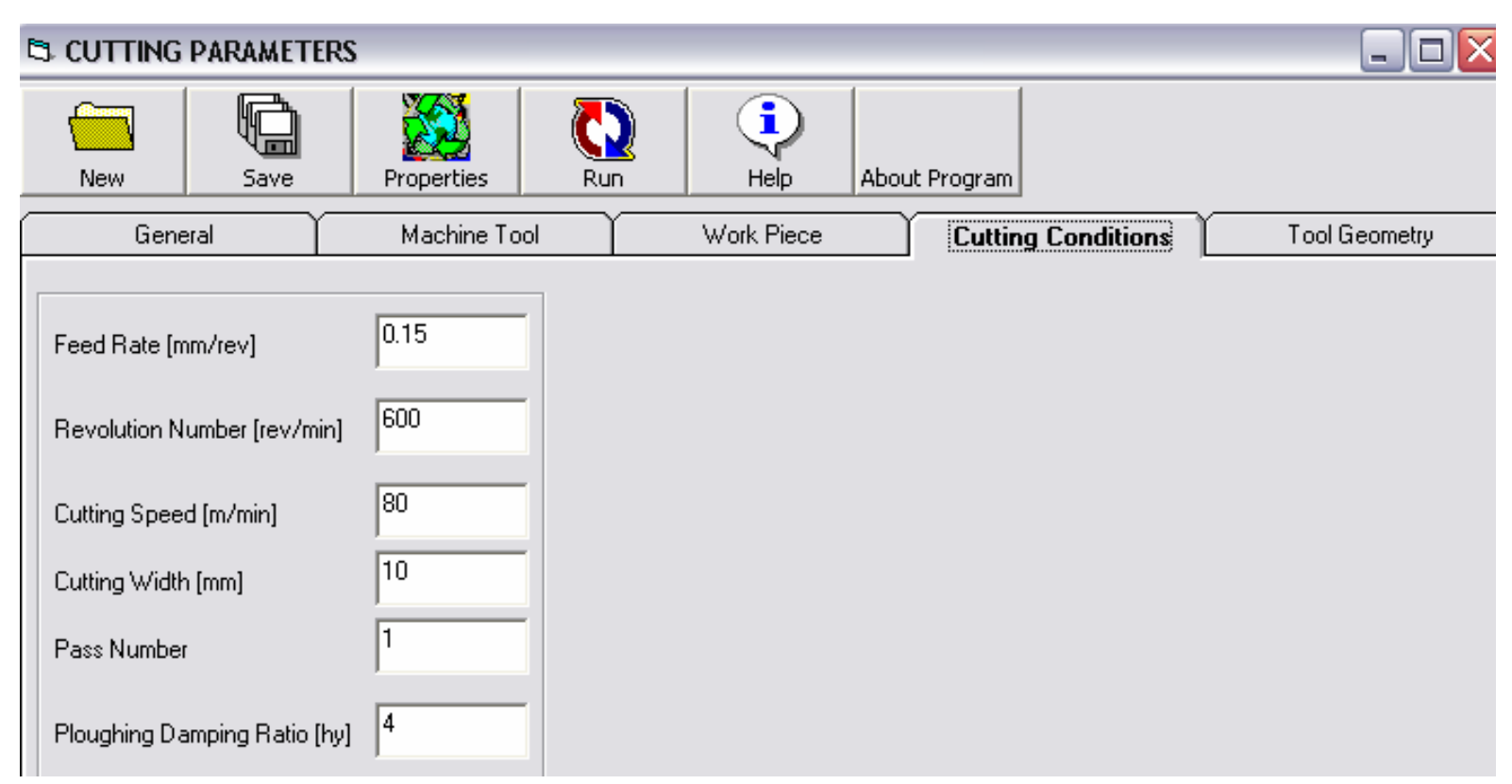

Figure 5 Selection of cutting parameters

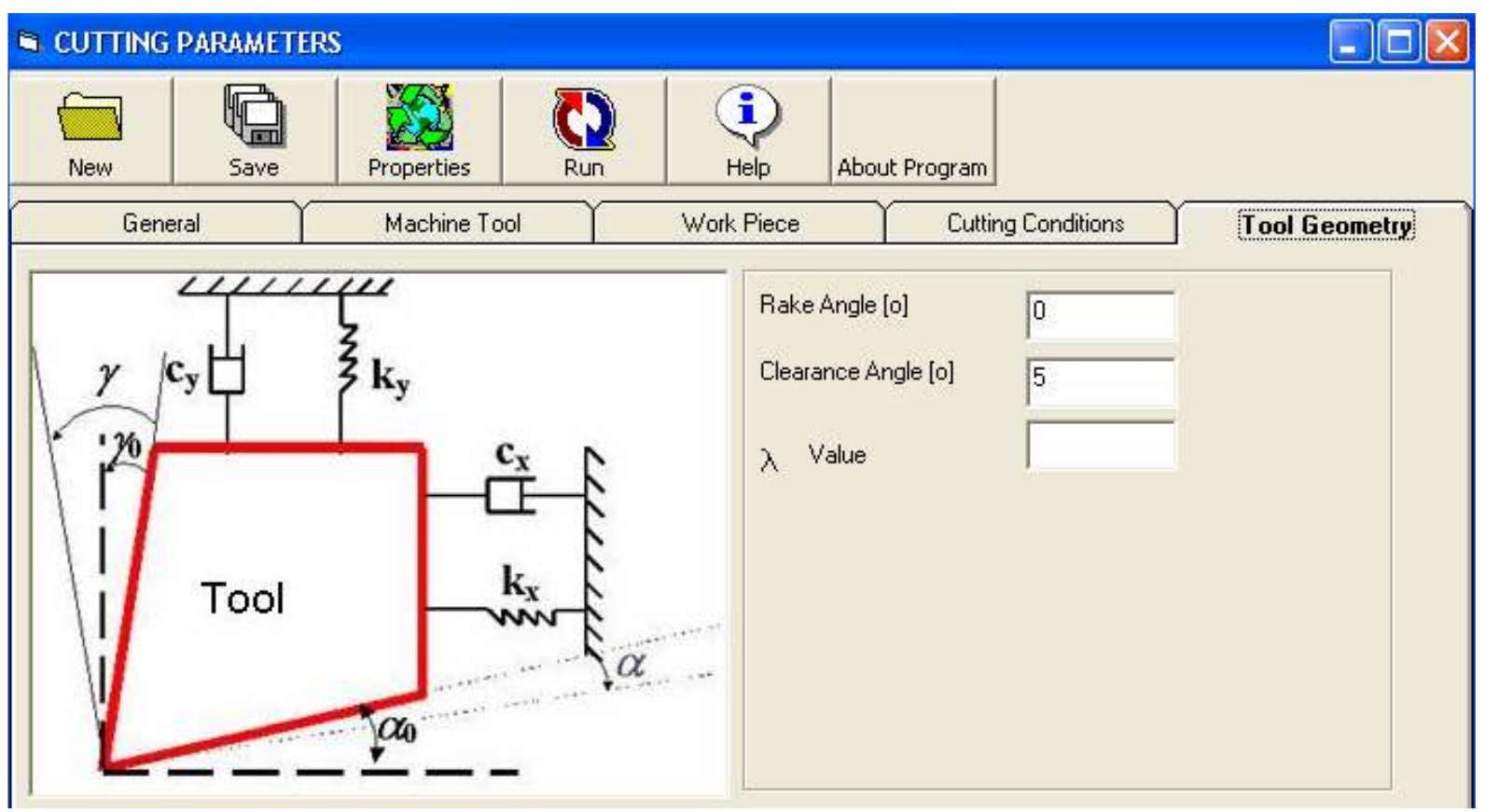

Figure 6 Selection of cutting tool geometry

$$
\begin{aligned}
& \bar{A}=-\dot{Y} \cos \gamma_{0}+\dot{X} \sin \gamma_{0} \\
& \gamma=\gamma_{0}-\tan ^{-1}\left(\frac{\dot{Y}}{\bar{V}+\dot{X}}\right)
\end{aligned}
$$




$$
\begin{aligned}
& \eta=\tan ^{-1}\left(\frac{\dot{Y}}{\bar{v}+\dot{X}}\right) \\
& \mu=d\left|\bar{u}_{r} s_{0} \omega_{n 1}\right|^{q} \\
& \beta=\tan ^{-1} \mu
\end{aligned}
$$

\section{Force equations:}

$$
\begin{aligned}
& \bar{F}_{R}=\frac{(1-Y)}{\lambda[\sin (\phi+\eta) \cos (\phi+\beta+\gamma)]} \\
& \bar{F}_{C}=\bar{F}_{R} \cos (\beta+\gamma) \quad \bar{F}_{t}=\bar{F}_{R} \sin (\beta+\gamma) \\
& \bar{F}_{y}=\bar{F}_{R} \sin \left(\beta-\gamma_{0}\right) \quad \bar{F}_{x}=\bar{F}_{R} \cos \left(\beta-\gamma_{0}\right)
\end{aligned}
$$

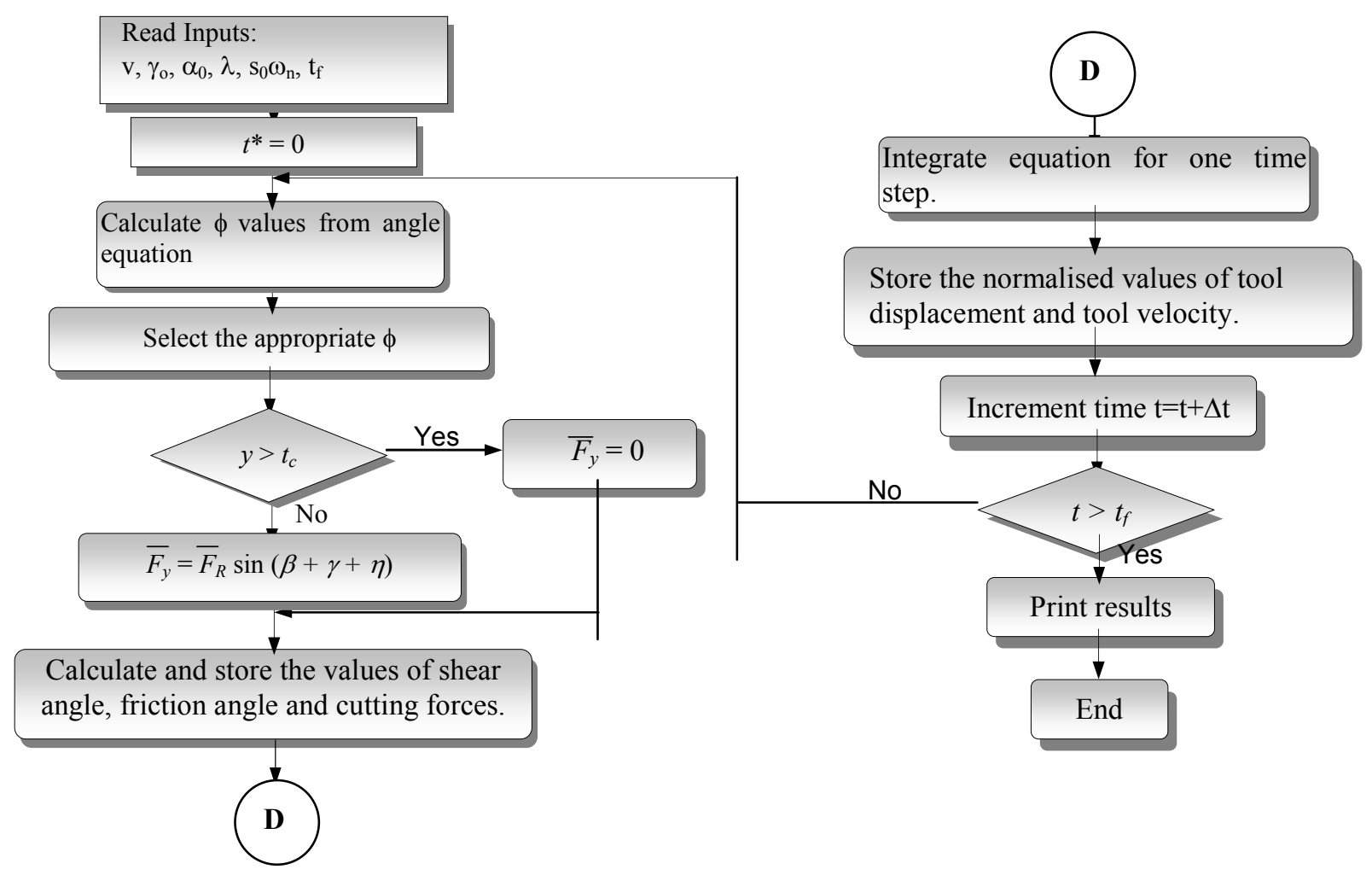

Figure 7 Flow chart of the numerical calculation procedure 


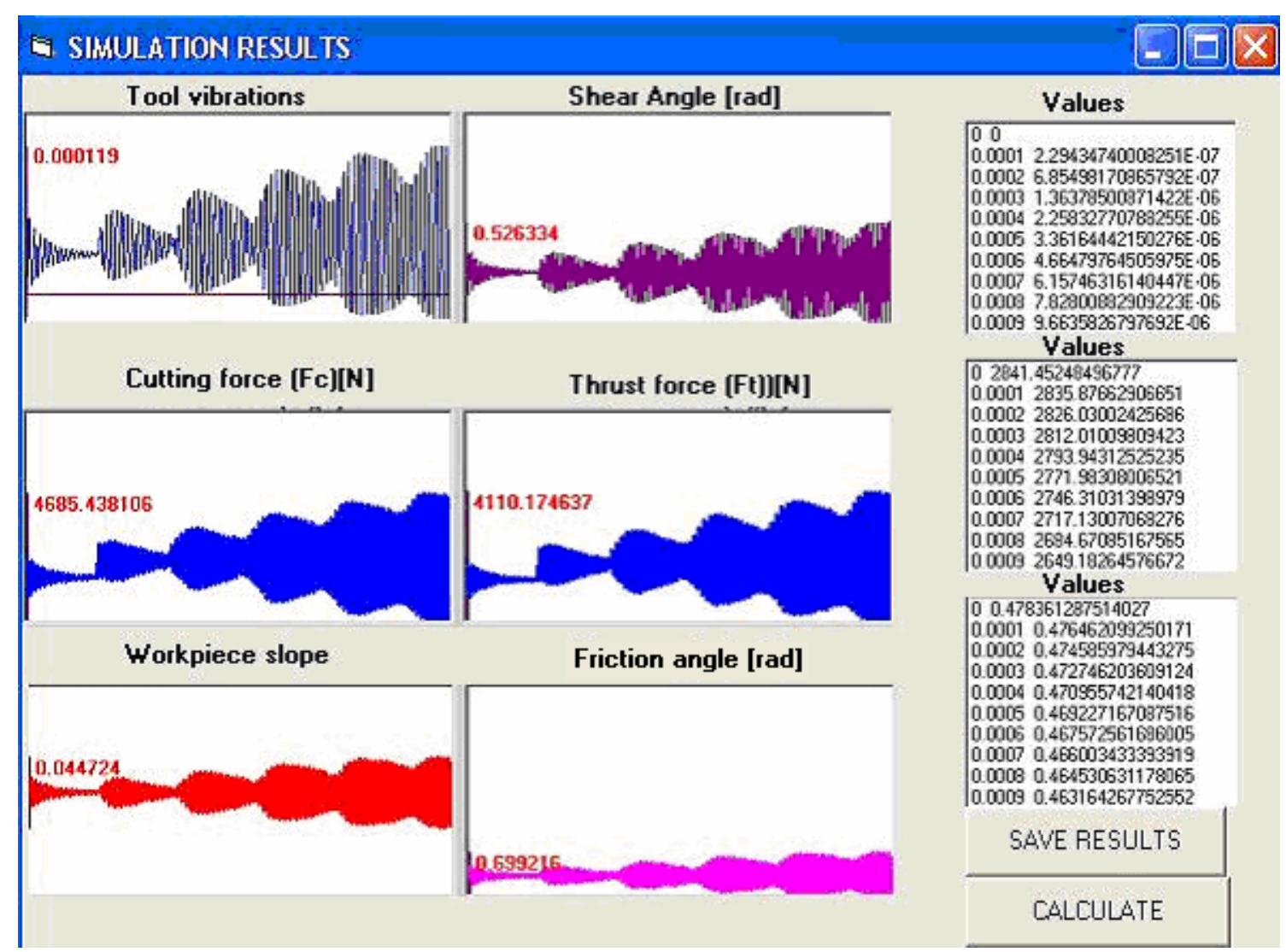

Figure 8 Result screen

Parameters used for the equations (2)-(8) are as follows:

$X \quad$ Dimensionless horizontal displacement of cutting tool in $x$ direction

$Y \quad$ Dimensionless vertical displacement of cutting tool in $y$ direction

$\gamma_{0} \quad$ Preset rake angle

$\omega_{n} \quad$ Natural frequency

$u_{r} \quad$ Chip velocity relative to the tool

$s_{0} \quad$ Feed rate

$\beta \quad$ Friction angle

$\mu \quad$ Friction coefficient

$F_{R} \quad$ Resultant force

$F_{C} \quad$ Cutting force

Ft Thrust force

$\lambda \quad$ Normalized force

$F_{x} \quad$ X-component of resultant force

$F_{y} \quad$ y-component of resultant force 
Dynamic equations:

$$
\begin{aligned}
& \ddot{Y}_{+}\left[2 \zeta_{1}+h_{y}\left|\frac{\eta}{\alpha}\right|\right] \dot{Y}+Y=\bar{F}_{y} \\
& \ddot{X}+2 \zeta_{2} \omega_{r} \dot{X}+h_{x}\left|\frac{\eta}{\alpha}\right| \dot{Y}+\omega_{r}{ }^{2} X=\bar{F}_{\mathrm{x}} \\
& \} \text { for } \dot{Y}<0 \\
& \ddot{Y}+2 \zeta_{1} \dot{Y}+Y=\bar{F}_{y} \\
& \ddot{X}+2 \zeta_{2} \omega_{r} \dot{X}+\omega_{r}{ }^{2} X=\bar{F}_{\mathrm{x}}
\end{aligned}
$$

The parameters used for the dynamic equations are,

$h x \quad$ Empirical process damping coefficient in $\mathrm{x}$ direction

hy Empirical process damping coefficient in y direction

$\zeta_{1} \quad$ Damping ratio of machine tool in $y$ - direction

$\zeta_{2} \quad$ Damping ratio of machine tool in $x$-direction

$\alpha \quad$ Instantaneous clearance angle

$t^{*} \quad$ Dimensionless time

$t_{C} \quad$ Uncut chip thickness

The initial conditions for the solution of dynamic equations are assumed to be as

follows:

$$
\begin{aligned}
& Y(0)=\dot{Y}(0)=0 \\
& X(0)=\dot{X}(0)=0
\end{aligned}
$$

\section{CONCLUSIONS}

This paper focuses on the vibration analysis of machine tools. In order to do these, a computer program which analyses chatter vibrations of machine tool with one and two degree of freedom is developed by using Visual Basic programming language. Based on the generated results, the following conclusions can be made:

a. The developed computer program is completely flexible and allows users to create their own specific applications. The vibrations that are encountered in machining can be predicted without need of any documents and simulation results can be shown graphically. Thus, suitable cutting conditions free from chatter can be obtained. Since the dynamic equations related to vibration analysis are very complex, these equations are solved numerically.

b. The results of the simulations that are carried out in a wide range of cutting conditions and tool geometries are in good agreement with the existing experimental data in the literature. Therefore, reliability of the developed model in predicting the effects of tool geometry and cutting conditions on tool vibration has been demonstrated.

c. Dynamic variations of tool displacement, shear angle, friction coefficient and cutting forces are presented graphically. Therefore, the user approaches the results step by step in analyzing vibration analyze. The computer program developed in this study may be used for teaching purposes in machine tool vibration in educational organizations.

\section{REFERENCES}


1. A. Taskesen and Y. Ercan, Theoretical analysis and prediction of machine tool stability and chatter vibration during orthogonal metal cutting with a one degree of freedom model, $11^{\text {th }}$ Machine Theory Symposium, Gazi.University, 2003.

2. A. Taskesen. and Y. Ercan, Theoretical analysis and prediction of machine tool stability and chatter vibration during orthogonal metal cutting with a two degree of freedom model, $11^{\text {th }}$ Machine Theory Symposium, Gazi.University, 2003.

3. M. Wiercigroch, Chaotic vibration of a simple model of the machine tool- cutting process system, ASME Journal of Engineering for Industry, 119, 468-475, 1997.

4. I. Yellowley, A simple predictive model of orthogonal metal cutting, International Journal of Machine Tools and Manufacturing, 27, 357-365, 1987.

5. E. Konodo, H. Ota and T. Kawai, A new method to detect regenerative chatter using spectral analysis, Part 1: Basic study on criteria for detection of chatter, Journal of Manufacturing Science and Engineering, 119, 461-466, 1997.

6. K. Jemielniak, A. Widota, Numerical simulation of non-linear vibration in turning, International Journal of Machine Tools and Manufacturing, 29, 239-247, 1989.

7. G. Tlusty, Manufacturing processes and equipment, New York, Prentice Hall, 2000. 